\title{
A Simple RP-HPLC Method to Simultaneously Assay the Contents of Lamivudine, Tenofovir, and Nevirapine in Fixed Dose Combined Oral Antiviral Medicines
}

\author{
Phoebe Esinam Goku (D), ${ }^{1}$ Emmanuel Orman ${ }^{1},{ }^{2}$ Anna Naa Kwarley Quartey, \\ Joseph Kwasi Adu $\left(\mathbb{D}^{3}{ }^{3}\right.$ and Reimmel Kwame Adosraku ${ }^{3}$ \\ ${ }^{1}$ Department of Pharmaceutical Sciences, School of Pharmacy, Central University, Accra 23321, Ghana \\ ${ }^{2}$ Department of Pharmaceutical Chemistry, School of Pharmacy, University of Health and Allied Sciences, Ho 23321, Ghana \\ ${ }^{3}$ Department of Pharmaceutical Chemistry, Faculty of Pharmacy and Pharmaceutical Sciences, \\ Kwame Nkrumah University of Science and Technology, Kumasi 23321, Ghana
}

Correspondence should be addressed to Emmanuel Orman; spytrano@gmail.com

Received 3 July 2020; Accepted 10 August 2020; Published 8 September 2020

Academic Editor: Patricia E. Allegretti

Copyright (C) 2020 Phoebe Esinam Goku et al. This is an open access article distributed under the Creative Commons Attribution License, which permits unrestricted use, distribution, and reproduction in any medium, provided the original work is properly cited.

\begin{abstract}
An accurate and rapid reverse HPLC method has been developed and validated for the simultaneous quantification of lamivudine, nevirapine, and tenofovir disoproxil fumarate. Suitable separation was achieved on Phenomenex Synergi C18 $(250 \times 4.6 \mathrm{~mm}, 4 \mu \mathrm{m})$ using mobile phase, methanol (50\%): ammonium acetate buffer (adjusted to $\mathrm{pH} 2.80$ ) (40\%): acetonitrile (10\%) in an isocratic mode. The drugs were detected at $270 \mathrm{~nm}$ with a flow rate of $1.0 \mathrm{ml} / \mathrm{min}$, and the retention times were found to be $3.26,5.42$, and 7.55 minutes for lamivudine, nevirapine, and tenofovir disoproxil fumarate, respectively. The developed method was validated per ICH guidelines. Good linearity was obtained within the concentration ranges of $10-59 \mu \mathrm{g} / \mathrm{ml}, 7-42 \mu \mathrm{g} / \mathrm{ml}$, and $15-90 \mu \mathrm{g} / \mathrm{ml}$ with a correlation coefficient of not less than 0.990 . The \% RSD values for precision (intraday and interday) and accuracy studies were found to be less than $2 \%$. The results obtained from quantitative analysis conform to USP content requirements for marketed tablet dosage forms, RICOVIR-LN, and tenofovir disoproxil fumarate/lamivudine tablets. The method is therefore useful for routine quality control of antiretroviral tablet dosage forms containing tenofovir disoproxil fumarate, lamivudine, and nevirapine.
\end{abstract}

\section{Introduction}

HIV/AIDS is a major public health issue and as such forms a significant part of the Sustainable Development Goals, with the aim of ensuring healthy lives and promoting well-being for all at all ages [1]. The introduction of highly active antiretroviral therapy (HAART), a treatment regimen comprising of the combination of three or more antiretroviral drugs [2], has revolutionized the management of the disease condition, with the resultant dramatic reduction in mortality rates and the incidences of opportunistic infections [3]. In Ghana and other parts of the world, three of the widely used antiretrovirals (ARVs) in HAART include lamivudine (3TC), nevirapine (NVP), and tenofovir disoproxil fumarate (TDF). It may be argued that a lasting impact on morbidity and mortality on people living with HIV/AIDS (PLWHA) could be assured if the quality of ARVs was adequately monitored. With recent reports of substandard medicines available in Ghanaian health facilities [4], it has become particularly important to increase surveillance on the quality of all medicines procured for public health facilities, especially for antiretrovirals, used for a significant public health intervention programme. This therefore calls for the development and validation of reliable analytical methods to achieve such quality control purposes.

In the past, most of the methods developed had focused on the detection and quantitation of ARVs in biological samples [5, 6]; just a handful had concentrated on methods 
for the oral dosage formulations [7-9]. In as much as these methods have provided useful tools to assess the qualities of some ARVs, it is necessary that very efficient alternative methods with the target scope of ARVs in the HAART programme be developed to achieve similar quality control outputs. The aim of the current study therefore was to develop a simple, affordable, and reliable method for the quality assessment of ARVs used in the HAART programme in Ghana and other parts of the world, where applicable. Thus, the method when developed would be used for the analyses of 3TC, NVP, and TDF in monotherapies and fixeddose combination products as well.

3TC is chemically known as 4-amino-1-[(2R,5S)-2(hydroxymethyl)-1,3-oxathiolan-5-yl]pyrimidin-2 $(1 H)$-one [10]. It is a nucleoside reverse transcriptase inhibitor and is available for the treatment of HIV-I and HIV-II infections, as well as hepatitis B virus [11]. TDF is a derivative of adenosine $S^{\prime}$-monophosphate and is a prodrug [11]. Chemically, it is known as [[(1R)-2(6-amino-9H-purin-9yl)-methylethoxy] methyl] phosphonate, bis (isopropyloxycarbonyloxymethyl ester), fumarate $(1: 1)$. It inhibits both HIV-I and HIV-II. It is a nucleotide analogue that is available for use in antiretroviral therapy [11]. NVP, on the other hand, belongs to the non-nucleoside reverse transcriptase inhibitor class of ARVs. Its chemical name is 11-cyclopropy 1-4-methy 1-5, 11-dihydro [3, 2b: $2^{\prime}, 3^{\prime}$-e] $[1,4]$ diazepin-6-one hemihydrate. It is approved for the treatment of HIV infections in adults and children in combination with other antiretroviral agents [11].

\section{Materials and Methods}

2.1. Standards and Samples. The working standards used for the study included confirmed 3TC (assay: 102.0\%), NVP (assay: $100.1 \%$ ), and TDF (assay: 100.2\%) (Table 1), which were donated by Danadams Pharmaceutical Industry Limited, Spintex, Ghana. The drug products, samples A1 (containing TDF $300 \mathrm{mg} / 3 \mathrm{TC} 300 \mathrm{mg}$ tablets + NVP $200 \mathrm{mg}$ ) and A2 (containing TDF $300 \mathrm{mg} / 3$ TC $300 \mathrm{mg}$ ) both claimed to be manufactured by Mylan Laboratories Limited, India, were used.

2.2. Chemicals and Reagents. The reagents and solvents used to prepare the samples and carry out the analyses were of analytical and HPLC grades, respectively. Solvents including acetonitrile and methanol were procured from Fisher Scientific, United Kingdom. Ammonium acetate and glacial acetic acid purchased from VWR International Limited and Merck House, respectively, were also used for the analysis. Purified water was freshly produced in-house, terminally sterilized with ultraviolet radiation, and filtered through a $0.45 \mu \mathrm{m}$ membrane filter before being used to prepare all solutions and buffers.

2.3. Equipment and Instrument. The HPLC system used comprised of Shimadzu prominence UFLC series system, consisting of LC-20A quaternary pump (part G1311 A), DGU-20A $\mathrm{A}_{5}$ in-line vacuum degasser (part no. G1322A), and
SPD-20A ultraviolet detector. Data acquisition was performed by LC solutions software (version A.10.02 Build 1757). The chromatographic separation was carried out using on a C18 Phenomenex Synergi column $(250 \times 4.6 \mathrm{~mm}$; $4 \mu \mathrm{m}$ ). An electronic analytical balance (Mettler Toledo, AB204-S/FACT), a digital $\mathrm{pH}$ meter (Mettler Toledo Seven Compact pH/Ion S220), and a sonicator were also used.

\subsection{Preparation of Solutions}

2.4.1. Buffer Preparation. A $500 \mathrm{ml}$ of $0.02 \mathrm{M}$ ammonium acetate buffer was prepared by weighing a determined quantity of ammonium acetate powder, dissolving with some amount of distilled water, and transferred into a $500 \mathrm{ml}$ volumetric flask. The $\mathrm{pH}$ was adjusted to 2.8 with acetic acid, and with continuous stirring, the solution was topped up with distilled water to the required volume. It was then filtered with a $0.45 \mu \mathrm{m}$ membrane filter.

2.4.2. Mobile Phase/Diluent Preparation. The solvent system used was a mixture of buffer $(\mathrm{pH}=2.8)$, methanol, and acetonitrile in the ratio $40: 50: 10(\mathrm{v} / \mathrm{v})$, respectively. This solution was also used as the diluent to prepare solutions of the standards and samples.

2.4.3. Preparation of Standard Solutions. A stock standard solution containing $75 \mathrm{mg}$ of $3 \mathrm{TC}, 35 \mathrm{mg}$ of NVP, and $50 \mathrm{mg}$ of TDF was prepared in a $100 \mathrm{ml}$ volumetric flask. The content in the flask was sonicated at $37^{\circ} \mathrm{C}$ for 10 minutes before topping up to the required volume with the diluent, after cooling. The resulting solution was filtered with a $0.45 \mu \mathrm{m}$ membrane filter. $3 \mathrm{ml}$ of the stock solution was pipetted to prepare $50 \mathrm{ml}$ of working standard solution containing $45 \mu \mathrm{g} / \mathrm{ml}$ of $3 \mathrm{TC}, 21 \mu \mathrm{g} / \mathrm{ml}$ of NVP, and $30 \mu \mathrm{g} / \mathrm{ml}$ of TDF.

2.4.4. Preparation of Sample Solutions. Solutions of powdered product samples A (containing TDF and 3TC) and B (containing two formulations, with $\mathrm{B}_{1}$ containing TDF and $3 \mathrm{TC}$ and $\mathrm{B}_{2}$ containing NVP) were prepared for analysis. For samples $A$ and $B_{1}$, a weight of each containing an equivalent of $75 \mathrm{mg}$ of 3TC was weighed and transferred into a $100 \mathrm{ml}$ volumetric flask. About $50 \mathrm{ml}$ of methanol was added, sonicated for 10 minutes at $37^{\circ} \mathrm{C}$, and made up to volume with the diluent. The resulting solution was then filtered through a Whatman No. 1 filter paper, discarding the first $5 \mathrm{ml}$ of the filtrate. $3 \mathrm{ml}$ of the resulting filtrate was pipetted and transferred into a $50 \mathrm{ml}$ volumetric flask and made up to volume using the diluent. For sample $\mathrm{B}_{2}$, a weight containing an equivalent of $35 \mathrm{mg}$ of NVP was transferred into a $100 \mathrm{ml}$ volumetric flask and a similar procedure as described above was employed to prepare the sample B solution.

2.5. Development and Validation of Method. The method for detection, separation, and quantitation of the three antiretroviral drug substances in the product was developed empirically (S1), and validated in accordance with the 
TABle 1: Chemical data on drug substances considered in the study.

$\begin{aligned} & \text { Drug } \\ & \text { substance }\end{aligned}$ Code
Lamivudine 3TC<smiles>CC(C)OC(=O)OCOP(=O)(CO[C@@H](C)Cn1cnc2c(N)ncnc21)OCOC(=O)OC(C)C</smiles>

Nevirapine NVP

International Council for Harmonisation (ICH) Q2(R) guidelines [12]. The validation parameters investigated included linearity and its range, limits of detection and quantitation, specificity, stability of test solution, robustness, accuracy, and precision.

2.5.1. Specificity/Selectivity. Specificity and selectivity were assessed by comparing the chromatograms from a matrix without expected analytes (blank sample) with that of matrices containing the expected analytes (that is, 3TC, NVP, and TDF) $[13,14]$. The selectivity/specificity was confirmed by comparing mean $\pm \mathrm{SD}$ of the retention times for the analytes using one-way ANOVA followed by Tukey's post hoc test [15].

2.5.2. Accuracy. Accuracy was investigated by determining recoveries of the analytes at three concentration levels $(80 \%$, $100 \%$, and $120 \%)[16,17]$.

2.5.3. Precision. Precision was demonstrated by determining repeatability (intraday precision) and intermediate precision of the method. Intraday precision was confirmed 
from the peak areas of the analytes, from triplicate injections of three dilute concentrations of the standard solution within the same day (that is, $15 \mu \mathrm{g} / \mathrm{ml}, 45 \mu \mathrm{g} / \mathrm{ml}$, and $90 \mu \mathrm{g} /$ $\mathrm{ml}$ for $3 \mathrm{TC} ; 7 \mu \mathrm{g} / \mathrm{ml}, 21 \mu \mathrm{g} / \mathrm{ml}$, and $42 \mu \mathrm{g} / \mathrm{ml}$ for NVP; and $10 \mu \mathrm{g} / \mathrm{ml}, 30 \mu \mathrm{g} / \mathrm{ml}$, and $59 \mu \mathrm{g} / \mathrm{ml}$ for $\mathrm{TDF})$. Intermediate precision, on the other hand, involved studying the variation in response at $100 \%$ concentration of the working standard on three different days. The results obtained were statistically analysed by determining the relative standard deviations and carrying out ANOVA, where applicable [12].

2.5.4. Linearity and Range. The linearity of the developed method was investigated by injecting six concentrations prepared from the stock standard solution, to obtain concentrations for 3TC, NVP, and TDF within the ranges of $15 \mu \mathrm{g} / \mathrm{ml}-90 \mu \mathrm{g} / \mathrm{ml}, 7 \mu \mathrm{g} / \mathrm{ml}-42 \mu \mathrm{g} / \mathrm{ml}$, and $10 \mu \mathrm{g} / \mathrm{ml}-59 \mu \mathrm{g} /$ $\mathrm{ml}$, respectively [12]. Triplicate determinations were carried out for each test concentration and the peak areas, reported as mean $\pm \mathrm{SD}$ were plotted against test concentrations. Statistical analysis was performed by the least-squares method [13]. Linearity was predicted by estimating the regression coefficient $\left(R^{2}\right)$ and the linear regression $y$-intercept of the response versus concentration plot. The regression model was also tested for fitness by determining the level of significance of the $F$-value of the model in an ANOVA at 5\% risk level [13]. Additionally, the residual plots for the sets of test data were generated.

2.5.5. Limit of Detection (LOD) and Limit of Quantitation (LOQ). The limits of detection and quantification were determined from the intercept on the $y$-axis slope from the linear regression model derived from the linearity test [12]. The formulae below were used for calculating the LOD and LOQ. The results are shown in Table 2.

$$
\begin{aligned}
& \text { LOD }=\frac{3.3 \times \text { standard deviation of the response }}{\text { slope of the calibration curve }}, \\
& \text { LOQ }=\frac{10 \times \text { standard deviation of the response }}{\text { slope of the calibration curve }} .
\end{aligned}
$$

2.5.6. Robustness. The robustness of the developed method was tested by monitoring the effects of deliberate changes in the flow rate $( \pm 0.1 \mathrm{ml} / \mathrm{min})$ and the wavelength of detection $( \pm 2 \mathrm{~nm})$ on the general performance of the developed method $[13,18]$.

2.5.7. Stability of Test Solution. The stability of the working standard solution was assessed over a 6-hour period at room temperature by monitoring the peak areas of the drug substances with time [13].

2.6. Analysis of Commercial Products. The contents of 3TC, NVP, and TDF in samples $A, B_{1}$, and $B_{2}$ as prepared above were assessed from peak areas from triplicate injections of the samples and applying the linear regression models obtained to the recorded peak areas.

\section{Results and Discussion}

3.1. Method Development. The chromatographic method was developed empirically, guided by the physicochemical properties like acid dissociation constant ( $\mathrm{pKa}$ ) and partition coefficient (cLogP) (Table 1). The conditions comprising suitable column, mobile phase composition, wavelength for analyte detection, flow rate, column temperature, and injection volume were determined empirically by monitoring the resolution, peak symmetry, and run time for the analytes (S1). The investigations resulted in the choice of a mobile phase system consisting of methanol (50\%), ammonium acetate buffer $\mathrm{pH}$ of $2.8(40 \%)$ and acetonitrile (10\%), and a flow rate of $1 \mathrm{ml} / \mathrm{min}$, among others (Table 3 ), which were then used to develop the chromatographic method (Figure 1).

3.2. Method Validation. The results from the validation are summarized in Table 2. In establishing the specificity and selectivity of the developed method, the chromatogram generated from the blank sample showed only noises, with no apparent peak observed within 0-20 minutes (S2). Upon injection of the working standard solutions (containing 3TC, NVP, and TDF), three resolved peaks were observed. It was further shown that the retention times for each of the analytes were different from each other $(p<0.0001$; Table 2$)$. The outcome showed that the method was capable of independently detecting the three analytes and distinguishing one from the other, thus specific and selective. In order to evaluate the quantifying power of the method, its accuracy was also determined. It was shown that the percentage recoveries obtained, complied with the acceptance criteria of $98 \%-102 \%[13,14]$ (with minimum deviations) over the concentration range, $80 \%-120 \%$ of test concentration for the three analytes (Tables 2 and S3).

The responses for 3TC, NVP, and TDF were showed to be linear within the ranges $15 \mu \mathrm{g} / \mathrm{ml}-90 \mu \mathrm{g} / \mathrm{ml}$, $7 \mu \mathrm{g} / \mathrm{ml}-42 \mu \mathrm{g} / \mathrm{ml}$, and $10 \mu \mathrm{g} / \mathrm{ml}-59 \mu \mathrm{g} / \mathrm{ml}$, respectively (Table 2 and Figure 2). The regression coefficient of correlation $\left(R^{2}\right)$ obtained for the abovementioned analytes was $0.9959,0.9948$, and 0.9971 , respectively. $F$-values from the linear regression models were also shown to be significant, further demonstrating strong correlations between the concentration of the analytes and peak area responses (Table 2). The method was shown to detect at least $5.5032 \mu \mathrm{g} / \mathrm{ml}, 3.1496 \mu \mathrm{g} / \mathrm{ml}$, and $3.9267 \mu \mathrm{g} / \mathrm{ml}$ of 3TC, NVP, and TDF, respectively. However, quantitation could only be carried out with the method when their concentrations were at least $16.6762 \mu \mathrm{g} / \mathrm{ml}, 9.5443 \mu \mathrm{g} / \mathrm{ml}$, and $10.0433 \mu \mathrm{g} / \mathrm{ml}$, respectively (Table 2 ).

Method precision was demonstrated with repeatability and intermediate precision (Tables 2 and S4). It was observed in both evaluations that the RSDs for the method responses (peak areas) were less than 2\%, proving their consistency and precision [12, 13]. In addition, it was 


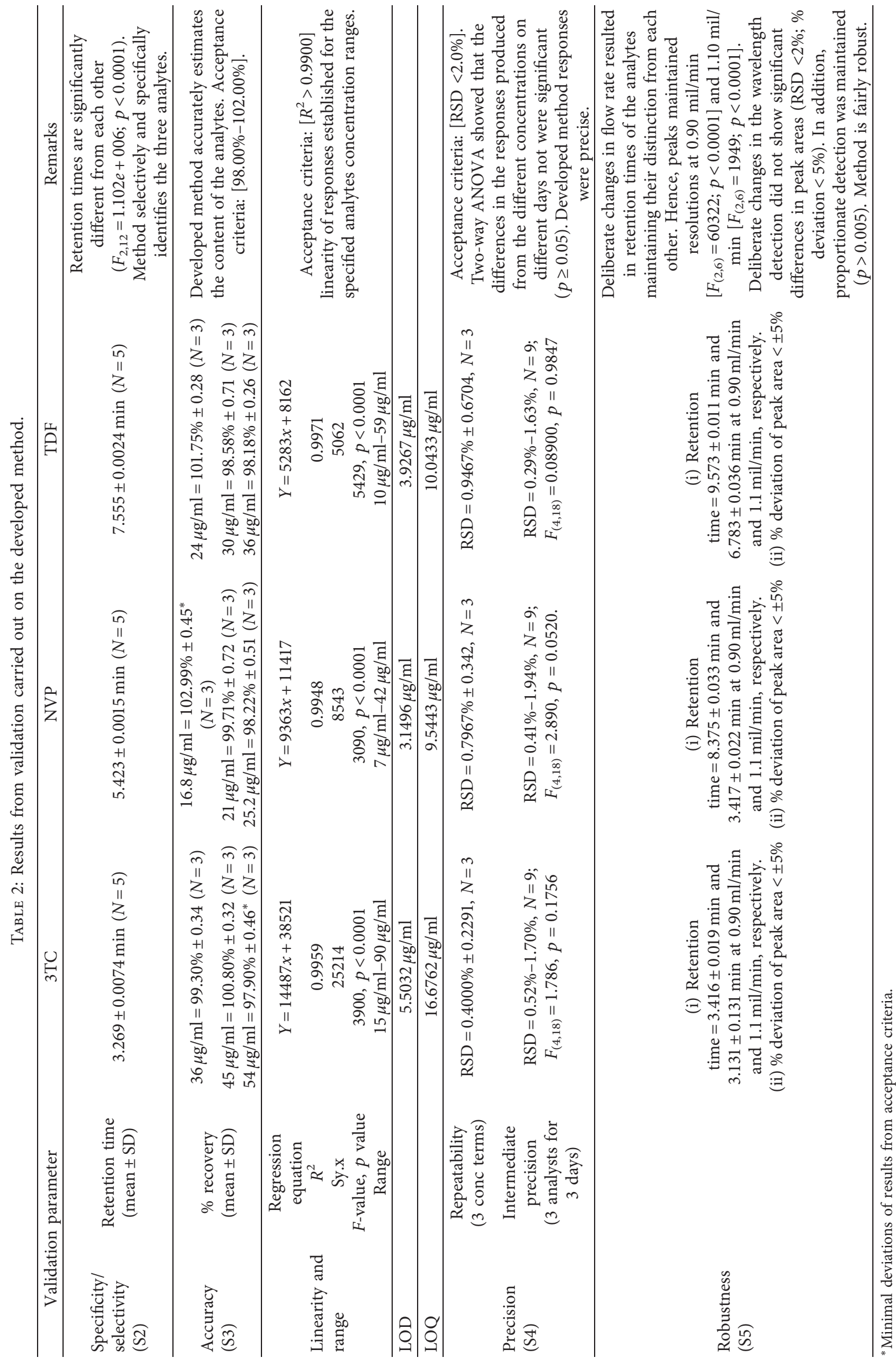


TABle 3: Optimised chromatographic conditions adopted for the validation.

\begin{tabular}{lc}
\hline Condition & Description \\
\hline Column & Phenomenex Synergi C18 $(250 \times 4.6 \mathrm{~mm}, 4 \mu \mathrm{m})$ \\
Mobile phase & Acetonitrile (10\%): ammonium acetate buffer (adjusted to $\mathrm{pH} 2.8)(40 \%):$ methanol $(50 \%)$ \\
Diluent & Acetonitrile (10\%): ammonium acetate buffer (adjusted to pH 2.8) $(40 \%):$ methanol $(50 \%)$ \\
Flow rate & $1 \mathrm{ml} / \mathrm{min}$ \\
Column temperature & $25^{\circ} \mathrm{C}$ \\
Injection volume & $10 \mu \mathrm{L}$ \\
Wavelength & $270 \mathrm{~nm}$ \\
\hline
\end{tabular}

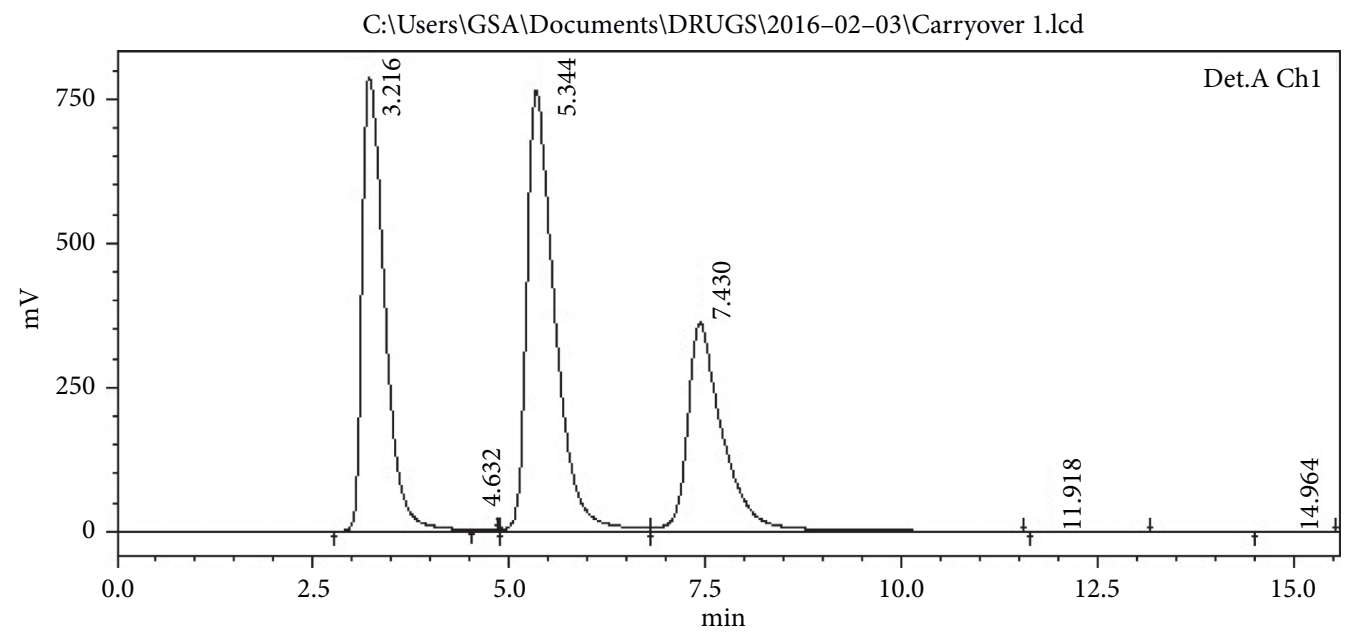

Figure 1: Chromatogram showing optimised separation of lamivudine (3.216 min), nevirapine (5.344 min), and tenofovir disoproxil fumarate standard (7.430 min) (from left to right) using the developed method.

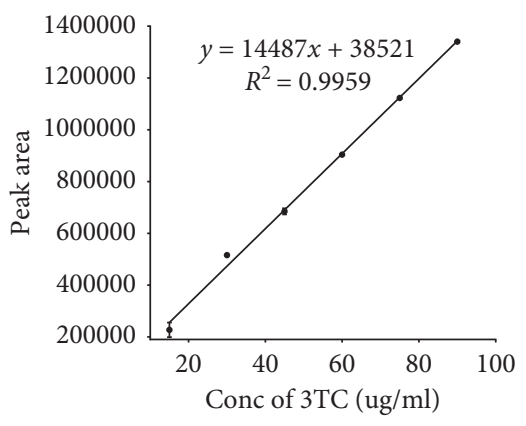

(a)

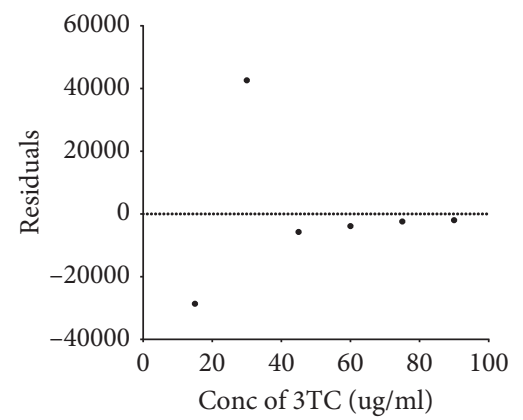

(d)

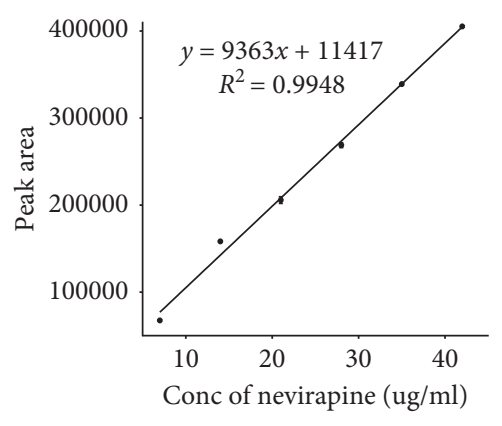

(b)

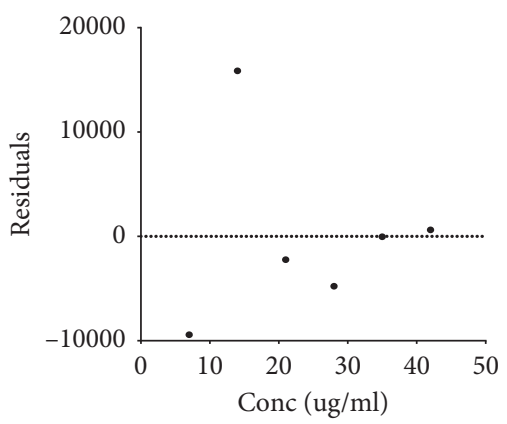

(e)

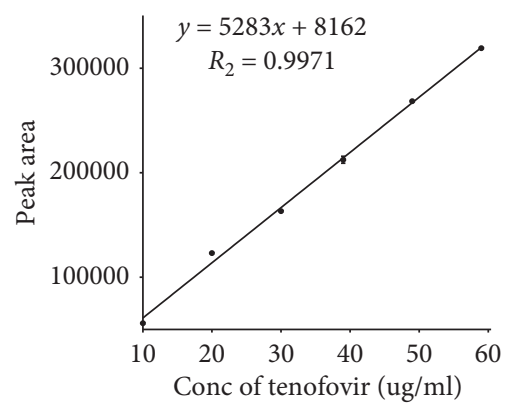

(c)

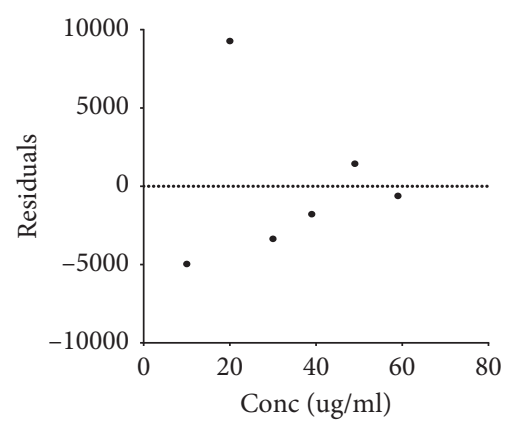

(f)

Figure 2: Proof of linearity of the developed method. (a) $A_{1}$, (b) $B_{1}$, (c) $C_{1}$, (d) $A_{2}$, (e) $B_{2}$, and (f) $C_{2}$. 


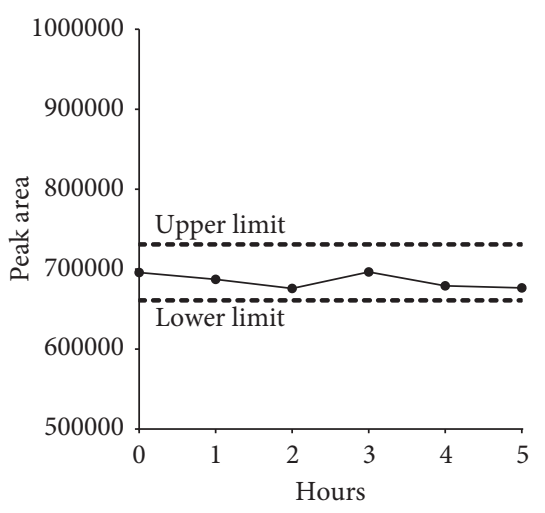

(a)

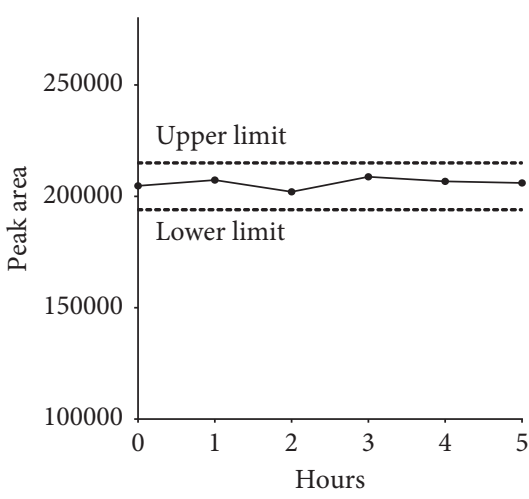

(b)

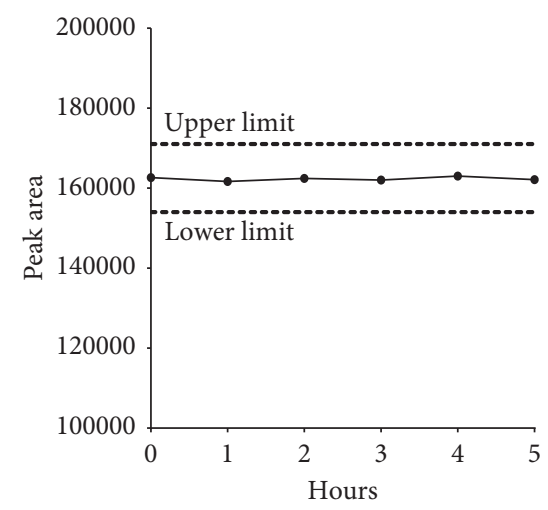

(c)

FIGURE 3: Stability of analytes in test solution within 6-hour period. (a) 3TC, (b) NVP, and (c) TDF.

TABle 4: Percentage content obtained for sampled products.

\begin{tabular}{|c|c|c|c|c|}
\hline & Analyte & Content (\%) & Acceptance criteria (\%) & Inference \\
\hline \multirow{2}{*}{ Sample A } & TDF & $97.50 \pm 0.75$ & & Passed \\
\hline & $3 \mathrm{TC}$ & $97.72 \pm 0.09$ & & Passed \\
\hline \multirow{2}{*}{ Sample $B_{1}$} & TDF & $98.55 \pm 0.17$ & $90-110$ & Passed \\
\hline & $3 \mathrm{TC}$ & $105.33 \pm 0.85$ & & Passed \\
\hline Sample $B_{2}$ & NVP & $99.20 \pm 1.17$ & & Passed \\
\hline
\end{tabular}

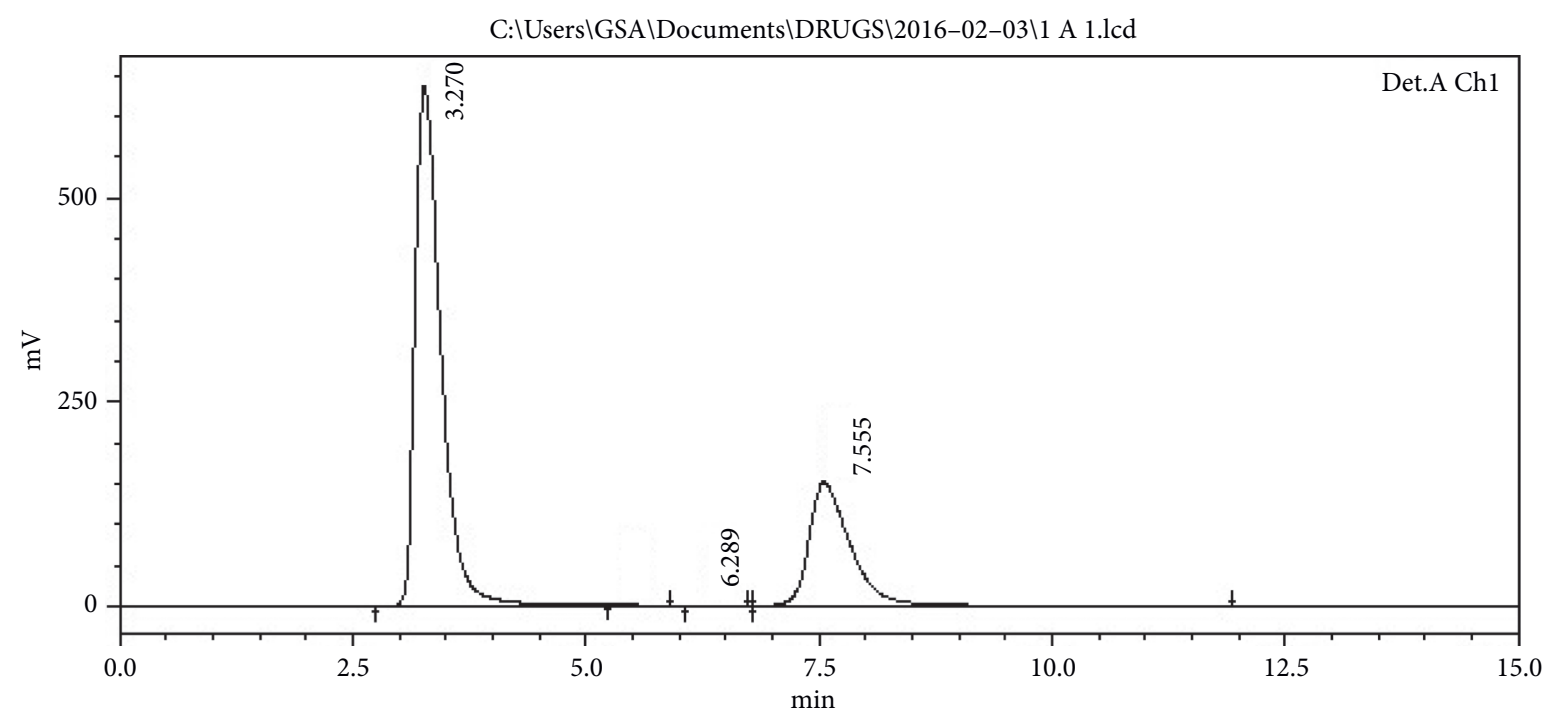

(a)

FIgUre 4: Continued. 


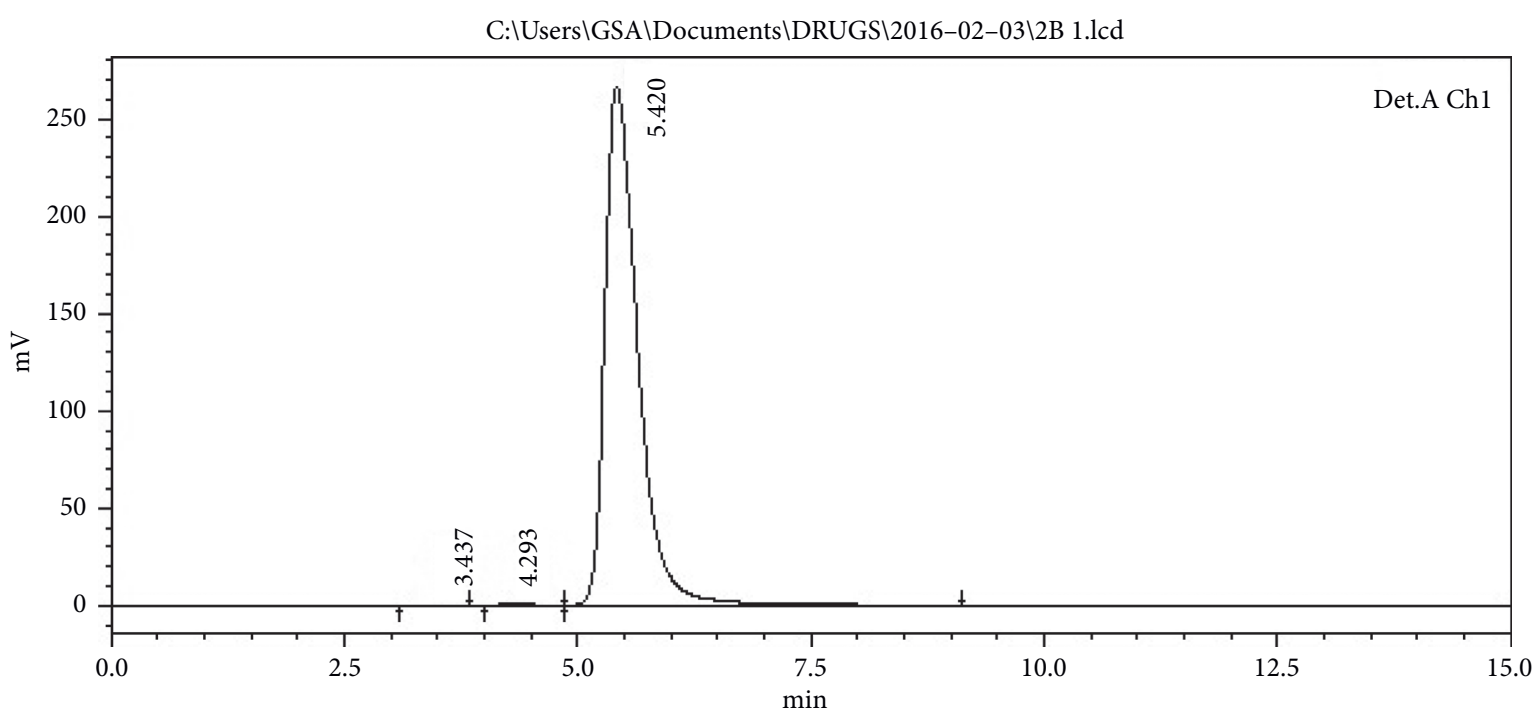

(b)

Figure 4: Chromatogram showing the peaks of lamivudine and tenofovir in a sample $\mathrm{B}_{1}$ and nevirapine in sample $\mathrm{B}_{2}$. Retention times are 3.27 and 7.55 minutes, and 5.42 minutes, respectively.

observed from the intermediate precision determinations that the peak areas recorded on different days for the different concentrations adopted were not significantly different from each other $\left(F_{(4,18)}=0.08900, p=0.9847\right)$ (Tables 2 and S4).

In testing for the robustness of the method, it was observed that deliberate changes in the flow rate did not significantly affect the resolution of the peaks, as they remained well separated from each other $\left(F_{(2,6)}=60322\right.$; $p<0.0001$ and $\left.F_{(2,6)}=1949 ; p<0.0001\right)$. Upon changes effected to the wavelength of detection, the deviations observed were also not significant (that is, \% deviations $< \pm 5 \%$ ) (Tables 2 and S5). Thus, the method was considered robust. The analytes in the test solution were also found to be stable within the period of analysis, which in the current study was estimated to be 6 hours (Figure 3).

3.3. Assay of Sampled Products. The validated method demonstrated its usability in the analysis of commercial products. The outcome of such investigation showed that the products complied with content assay specifications as indicated in the United States Pharmacopeia [19] (Table 4 and Figure 4).

\section{Conclusion}

An accurate, precise, and selective reverse HPLC method for the simultaneous estimation of lamivudine, nevirapine, and tenofovir disoproxil fumarate has been developed and validated. The method was validated per the $\mathrm{ICH}$ guidelines and passed all tests for the various validation parameters. The developed method is specific and selective as well as robust, accurate, and precise. The HPLC method was successfully applied to quantitatively estimate the active pharmaceutical ingredients in commercial products $\mathrm{A}_{1}$ (containing TDF $300 \mathrm{mg} / 3 \mathrm{TC}$ $300 \mathrm{mg}$ tablets + NVP $200 \mathrm{mg}$ ) and $\mathrm{A}_{2}$ (containing TDF $300 \mathrm{mg} / 3 \mathrm{TC} 300 \mathrm{mg}$ ).

\section{Data Availability}

Processed data used to support the findings of this study are included within the article. Some of the data related to the validation of the developed method are also included within the article while others are included as Supplementary Data (S1-S5).

\section{Conflicts of Interest}

The authors declare that they have no competing interests.

\section{Acknowledgments}

The authors are grateful to Danadams Pharmaceutical Industry Limited, Spintex, Accra, for the donation of the pure antiretroviral APIs used in this research. The authors are also thankful to Mr. Brown of Ghana Standards Authority for providing HPLC instrument and all reagents used.

\section{Supplementary Materials}

S1: investigations carried out to determine suitable chromatographic conditions in method development. S2: specificity/selectivity. S3: results for accuracy studies involving analytes. S4: precision repeatability-triplicate injections of three different concentrations of the analytes, to investigate the effect of concentration change on the precision of the method. S5: robustness examining effects from change in flow rate. (Supplementary Materials) 


\section{References}

[1] D. Lee, G. Pulawska, and J. Morton, Implementation Guide For the Sustainable Development GoalsAsia-Europe Foundation (ASEF), Singapore, 2017.

[2] J. S. Eggleton and S. Nagalli, Highly Active Antiretroviral Therapy (HAART) Treasure IslandStatPearls Publishing (Internet), Treasure Island, FL, USA, 2020.

[3] C. O. Elson and P. D. Smith, "Immunologic disease of the gastrointestinal tract," in Clinical Immunology, Mosby, Maryland, MO, USA, 3rd edition, 2008.

[4] S. Bekoe, "Exposure of consumers to substandard antibiotics from selected authorized and unauthorized medicine sales outlets in Ghana," Tropical Medicine \& International Health, vol. 25, no. 8, pp. 962-975, 2020.

[5] N. Charbe, S. Baldelli, V. Cozzi, S. Castoldi, D. Cattaneo, and E. Clementi, "Development of an HPLC-UV assay method for the simultaneous quantification of nine antiretroviral agents in the plasma of HIV-infected patients," Journal of Pharmaceutical Analysis, vol. 6, no. 6, pp. 396-403, 2016.

[6] E. Mariño, V. Albert, M. Ferrer, P. Modamio, and C. Lastra, "Development and validation of laboratory methods for antiretroviral quantitation using HPLC," Farmacia Hospitalaria, vol. 30, no. 6, 2006

[7] A. Garg, L. Kumar Soni, S. G. Kaskhedikar et al., "Development and validation of HPLC method for analysis of some antiretroviral agents in their pharmaceutical dosage forms," Pharmaceutical Chemistry Journal, vol. 43, no. 6, pp. 369-374, 2009.

[8] M. K. Jocelyn, M. M. Augustin, M. P. Adelard, M. K. Jeremie, and K. M. Tresor, "Development and validation of HPLC methods for simultaneous analysis of 6 antiretrovirals in pharmaceutical formulations," Journal of Analytical \& Pharmaceutical Research, vol. 8, no. 6, pp. 200-207, 2019.

[9] E. Mwando, A. Massele, E. Sepako, and K. Sichilongo, "A method employing SPE, MRM LC-MS/MS and a THF-water solvent system for the simultaneous determination of five antiretroviral drugs in human blood plasma," Analytical Methods, vol. 9, no. 3, pp. 450-458, 2017.

[10] BPC British Pharmacopoeia, The Stationery Office on behalf of the Medicines and Healthcare products Regulatory Agency (MHRA), BPC British Pharmacopoeia, London, UK, 2013th edition, 2012.

[11] C. Flexner, "Antiretroviral agents and treatment of HIV infection," "Antiretroviral agents and treatment of HIV infection," in Goodman and Gilman's The Pharmacological Basis of Therapeutics, L. Brunton, J. Lazo, and K. Parker, Eds., McGraw Hill Companies, New York, NY, USA, 11th edition, 2006.

[12] ICH, "Validation of Analytical Procedures: Text and Methodology Q2 (R1)," International Conference on Harmonization of Technical Requirements For Registration of Pharmaceuticals For Human Use, ICH Harmonized Tripartite Guideline, Federal Register. pp. 1-13, 2005.

[13] R. Bonfilio, E. C. L. Cazedey, M. B. D. Araújo, and H. R. Nunes Salgado, "Analytical validation of quantitative high-performance liquid chromatographic methods in pharmaceutical analysis: a practical approach," Critical Reviews in Analytical Chemistry, vol. 42, no. 1, pp. 87-100, 2012.

[14] C. Okai, E. Orman, and A. Agyenim-Boateng, "Validation of titrimetric-UV spectrophotometric method for the simultaneous quantification of paracetamol, caffeine and ibuprofen in pharmaceutical dosage forms," British Journal of Pharmaceutical Research, vol. 12, no. 4, pp. 1-14, 2016.
[15] J. K. Adu, C. D. K. Amengor, N. Kabiri et al., "Validation of a simple and robust liebermann-burchard colorimetric method for the assay of cholesterol in selected milk products in Ghana," International Journal of Food Science.vol. 2019, pp. 1-7, 2019.

[16] R. Heydari, "A new HPLC method for the simultaneous determination of acetaminophen, phenylephrine, dextromethorphan and chlorpheniramine in pharmaceutical formulations," Analytical Letters, vol. 41, no. 6, pp. 965-976, 2008.

[17] E. Garc1, A. Garc1, and C. Barbas, "Validation of a HPLC quantification of acetaminophen, phenylephrine and chlorpheniramine in pharmaceutical formulations: capsules and sachets," Journal of Pharmaceutical and Biomedical Analysis, vol. 29, pp. 701-714, 2002.

[18] A. Acheampong, W. O. Gyasi, G. Darko, J. Apau, and S. Addai-Arhin, "Validated RP-HPLC method for simultaneous determination and quantification of chlorpheniramine maleate, paracetamol and caffeine in tablet formulation," Springerplus, vol. 5, no. 1, 2016.

[19] USP, United States Pharmacopeia, USP 30/ NF. United States Pharmacopoeial Convention, 2006. 